\title{
El escenario deseado para la enfermería latinoamericana
}

\author{
The Desired Scenario for Latin American Nursing \\ O cenário desejado para a enfermagem latino-americana
}

DOI: 10.5294/aqui.2015.15.4.1

Beatriz Sánchez H. $^{1}$

Varios interrogantes con respecto al escenario deseado para la enfermería latinoamericana están por resolverse y, quizás, al hacerlo de manera adecuada, se logre un mayor impacto. ¿En dónde y cómo se proyecta a veinte años la enfermería en la región? ¿Qué estamos haciendo para ello? ¿Cuáles son las características y cuál el desempeño que debe tener la enfermería latinoamericana para cuidar mejor la experiencia de la salud en cada integrante de la población? ¿Cuáles son sus retos y sus fortalezas comunes?

Para responder estas y otras preguntas similares, se han realizado algunos ejercicios de prospectiva y planeación regional de un valor incalculable $(1,2)$. No se registran, empero, propuestas que cuenten con un enfoque integrado de prospectiva y estrategia.

La planeación prospectiva es un proceso que permite concentrar la atención sobre el futuro deseado para orientar la trayectoria de los eventos con miradas integrales y creativas a partir de acuerdos convergentes (3). Cuando a este proceso se le suma una estrategia para asegurar la toma de decisiones óptimas en cada momento, se logra consolidar una herramienta poderosa de liderazgo aplicable en múltiples ámbitos, que incluyen el desarrollo de la enfermería en América Latina.

Al mirar la historia de la enfermería en la región, es indiscutible su paso de la profesionalización al profesionalismo, hecho

1 Enfermera MScNsg. Profesora Catedrática Universidad de La Sabana. Profesora Especial Universidad Nacional de Colombia. que sucede de manera heterogénea y en muchos casos apoyado en la transferencia de procesos desarrollados para otros contextos e incluso por ensayo y error. A pesar de ello, a nivel regional se ha afianzado la regulación profesional (4), han aumentado las instituciones formadoras de enfermeros(as) y el nivel de formación, se ha logrado un avance en la consolidación y aceptación del objeto de estudio, se ha incrementado el trabajo en red y se han ampliado los roles tradicionales de asistencia, administración, docencia e investigación, para incorporar otros elementos y nuevos roles con mayor impronta de liderazgo, innovación e incursión en la política púbica $(5,6)$. Sin embargo, y a pesar de la magnitud de su fuerza constructora y comprometida, no puede afirmarse lo mismo sobre la visibilidad de la enfermería latinoamericana, ni sobre su aporte a la transformación de la realidad social regional en medio de sistemas de salud que no responden a las necesidades de la población.

Será preciso iniciar en cada país un ejercicio que aporte a su propio desarrollo y que, a su vez, contribuya como insumo para generar una mirada transversal en la región. Valdría la pena reunir a nivel nacional fuerzas representativas de diversos sectores como las asociaciones nacionales de enfermería y las de escuelas o facultades, los tribunales éticos, la representación del nivel decisorio del Estado, las representaciones locales de instancias internacionales de enfermería y algunos líderes de grupos reconocidos en la construcción del desarrollo profesional a nivel teórico-conceptual, académico, asistencial o investigativo, para que de manera conjunta desarrollen este tipo de planeación sumada 
a la estrategia. Pueden ser aportes significativos para el análisis los planteamientos estructurados de los usuarios y los de otros integrantes del equipo de salud. Una vez se logre determinar el futuro deseado y proponer la estrategia que lo garantice, esos aportes podrán ser insumo importante para proyectar el desarrollo requerido por la enfermería en América Latina.
En ejercicio de la autonomía de enfermería a nivel regional, es preciso definir el escenario deseado y establecer la estrategia para llegar a él. El empleo de estas herramientas metodológicas permite facilitar y sistematizar la reflexión colectiva pero, ante todo, respalda el desarrollo de una enfermería que se reconozca y se haga visible, en especial por su aporte a la salud.

\section{Referencias}

1. Manfredi M. El desarrollo de enfermería en América Latina: una mirada estratégica. Rev Latino-Am Enfermagem [Internet]. Enero 1993 [Visitado 2015 septiembre 25]; 1(1):23-35. Disponible en: http://www.scielo.br/scielo.php?script=sci_ arttext\&pid=S0104-11691993000100004\&lng=en. http://dx.doi.org/10.1590/S0104-11691993000100004.

2. Nájera RM, Castrillón MC. La enfermería en América Latina. Situación actual, áreas críticas y lineamientos para un Plan de Desarrollo [Internet]. [Visitado 2015 septiembre 25]. Disponible en: http://www.aladefe.org/articulos/la_enfermeria_en_america_latina.pdf

3. Godet M, Coates JF, Radford K. Creating Futures: Scenario Planning As a Strategic Management Tool. Washington, D.C: Economica Brookings Diffusion; AÑO. p. 280.

4. Regulación de la Enfermería en América Latina [Internet]. 2011 [Visitado 2015 septiembre 25]. Disponible en: http://www.paho.org/hq/index.php?option=com_content\&view=article\&id=6405\%3A2012-regulacion-enfermeriaamerica-latina\&catid=526\%3Ahuman-resources-health\&Itemid=2054\&lang=es

5. Malvárez SM, Castrillón MC. Panorama de la Fuerza de Trabajo en Enfermería en América Latina. Washington, D.C.: Organización Panamericana de la Salud [Internet]. 2005 [Visitado 2015 septiembre 25]. Disponible en: http://www.ops. org.bo/textocompleto/ift26346.pdf

6. Organización Mundial de la Salud, Organización Panamericana de la Salud. Acerca de Enfermería [Internet]. [Visitado 2015 septiembre 25]. Disponible en: http://www.paho.org/hq/index.php?option=com_content\&view=article\&id=1117 0\&Itemid=41547\&lang=en 